\title{
Multi-scale interactions between local hydrography, seabed topography, and community assembly on cold-water coral reefs
}

\author{
L.-A. Henry ${ }^{1}$, J. Moreno Navas ${ }^{1}$, and J. M. Roberts ${ }^{1,2,3}$ \\ ${ }^{1}$ Centre for Marine Biodiversity and Biotechnology, School of Life Sciences, Heriot-Watt University, Edinburgh, UK \\ ${ }^{2}$ Scottish Association for Marine Science, Scottish Marine Institute, Oban, UK \\ ${ }^{3}$ Center for Marine Science, University of North Carolina at Wilmington, Wilmington, NC, USA
}

Correspondence to: J. M. Roberts (j.m.roberts@hw.ac.uk)

Received: 12 November 2012 - Published in Biogeosciences Discuss.: 12 December 2012

Revised: 26 March 2013 - Accepted: 1 April 2013 - Published: 24 April 2013

\begin{abstract}
We investigated how interactions between hydrography, topography and species ecology influence the assembly of species and functional traits across multiple spatial scales of a cold-water coral reef seascape. In a novel approach for these ecosystems, we used a spatially resolved complex three-dimensional flow model of hydrography to help explain assembly patterns. Forward-selection of distance-based Moran's eigenvector mapping (dbMEM) variables identified two submodels of spatial scales at which communities change: broad-scale (across reef) and fine-scale (within reef). Variance partitioning identified bathymetric and hydrographic gradients important in creating broad-scale assembly of species and traits. In contrast, fine-scale assembly was related more to processes that created spatially autocorrelated patches of fauna, such as philopatric recruitment in sessile fauna, and social interactions and food supply in scavenging detritivores and mobile predators. Our study shows how habitat modification of reef connectivity and hydrography by bottom fishing and renewable energy installations could alter the structure and function of an entire coldwater coral reef seascape.
\end{abstract}

\section{Introduction}

Fundamental differences in species' ecology have important implications for ecosystems and their functioning. Traits such as dispersal, feeding mode and growth rate govern the ways in which organisms interact and use resources. Habitat modification can therefore invoke shifts in both the species and trait composition of communities (their "assembly"), with subsequent effects on processes such as nutrient cycling, metabolism and respiration depending on the spatial scale at which these traits are important in an ecosystem (De Bello et al., 2010). Ultimately, variability in species and trait distribution affects the delivery of ecosystem goods and services (Lavorel et al., 2011) and the distribution of whole ecosystems (Reu et al., 2011). This makes the preservation of species traits and ecosystem multifunctionality paramount to mitigate global declines in biodiversity (Cadotte et al., 2011; Mouillot et al., 2011).

Predictions about ecosystem functioning confronted with critical issues such as species loss, habitat fragmentation and climate change are hampered by community assembly models dominated by single-scale taxonomically narrow approaches. This impairs our perception of which processes are important because even distantly related taxa may be functionally equivalent. Functional equivalence is especially prevalent on coral reefs where niches overlap and competition between phylogenetically distinct species is high. Although environmental gradients can explain faunal turnover of sessile reef organisms (Vroom et al., 2005; Becking et al., 2006), this sessile "guild" is comprised of a diverse set of taxa such as macroalgae, sponges, corals, crinoids and bivalves. However the spatial scale at which these relationships emerge depends on species' ecology. Sessile organisms with restricted dispersal may be spatially autocorrelated at smaller scales (Blanquer et al., 2009), but their broader scale distributions governed by environmental gradients (Becking et al., 2006; de Voogd et al., 2006). Therefore taxonomically narrow approaches cannot answer ecologically compelling questions about the importance of environmental 
versus stochastic processes across functional guilds or spatial scales (Weiher et al., 2011).

Our study seeks to overcome the limitations of previous studies. We tested whether there are salient features of assembly across a phylogenetically diverse set of organisms inhabiting a cold-water coral reef ecosystem formed by the coral Lophelia pertusa (Scleractinia) at the Mingulay Reef Complex off western Scotland. Detailed, spatially contiguous high-resolution maps of seabed bathymetry have been derived from multibeam remote sensing surveys of the Lophelia reefs at Mingulay (Roberts et al., 2005a, 2009). Changes in bathymetry create faunal turnover across the complex (Henry et al., 2010), but the effects of hydrography on the reef fauna have not been quantified. Local hydrographic regimes affect particle encounter rates and thus food supply to Lophelia reefs (Thiem et al., 2006) and should affect the distribution of organisms that depend on currents for their food such as sessile filter and suspension feeders. At larger spatial scales, hydrography-mediated carbon flux can also limit body size across a broader range of functionally different organisms inhabiting the deep marine realm (McClain et al., 2012).

In situ lander-based measurements revealed tidally driven downwelling of surface waters and advection of turbid bottom waters at Mingulay, which are the likely key fooddelivery mechanisms for these communities (Davies et al., 2009; Duineveld et al., 2012). A new spatially resolved hydrographic model of the reef complex has been developed (Moreno Navas et al., 2013) using 3DMOHID (Modelo Hidrodinámico). Complex flow models in 3DMOHID are programmed using ANSI FORTRAN 95 with typical applications in coastal circulation, nutrient load, water exchange and aquaculture scenarios (Moreno Navas et al., 2011). As a predictive tool, this new model provides the first dynamic mathematical three-dimensional model of hydrography on a cold-water coral reef that can be used to model biodiversity.

The use of spatial eigenfunctions is also an emerging tool for ecologists that can be used to dissect the spatial structure in biological communities. One particular method, distance-based Moran's eigenvector mapping (dbMEM, formerly called principal coordinates of neighbour matrices, PCNM), is based simply on geographical co-ordinates, their pairwise distances and the minimum distance between sites that preserves their overall spatial connectivity (Borcard and Legendre, 2002). Positive eigenfunctions maximise Moran's index of spatial autocorrelation with respect to an initial spatial matrix of distances (Dray et al., 2006). Therefore these eigenfunctions can be used to distinguish effects of spatial autocorrelation from those created by purely environmental gradients (Borcard et al., 2004).

In a novel approach, we explored the wealth of relationships between local hydrography, bathymetry, species' ecology and community assembly across multiple spatial scales to provide a framework that will vastly improve our

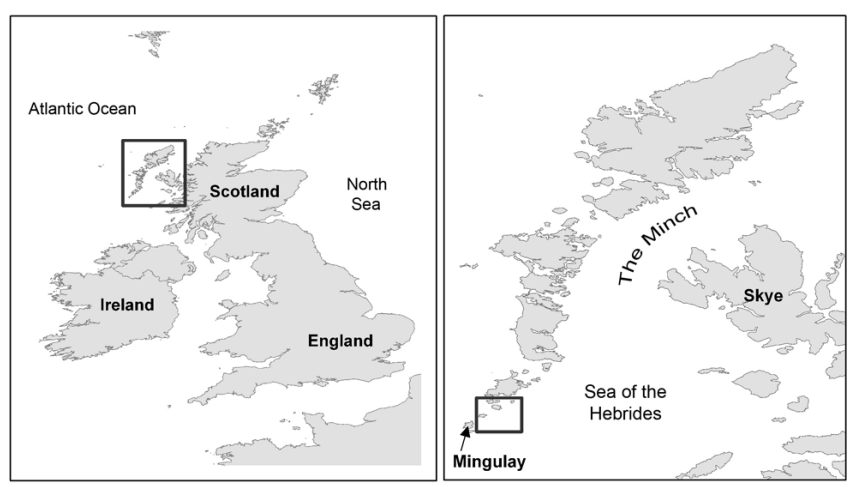

Fig. 1. Regional setting of the Mingulay Reef Complex in the Sea of the Hebrides, western Scotland.

appreciation of how human activities and climate change may impact the functioning of these reef ecosystems.

\section{Methods}

\subsection{Study area}

The Mingulay Reef Complex is a seascape of aphotic coral reefs formed by the azooxanthellate hard coral Lophelia pertusa in the Sea of the Hebrides at water depths of approximately 120-190 m (Fig. 1; Roberts et al., 2009). Individual reefs form mounds up to $5 \mathrm{~m}$ high (Roberts et al., 2005a), with strong currents downwelling and impinging on the rough topography of the seabed and supplying food to reef fauna (Duineveld et al., 2012). Together, bathymetric variability and hydrography affect the biodiversity of reef organisms (Henry et al., 2010) and the distribution of shark spawning grounds (Henry et al., 2013) on the reef complex.

Two reefs were examined in this study (Fig. 2): Mingulay Area 1 (MRC1) and Mingulay Area 5 North (MRC5N). The former is a $4 \mathrm{~km}$ long ridge oriented east to west. The northfacing aspect of this ridge slopes gently and supports welldeveloped coral mounds near a gap in the ridge in contrast to the south-facing side that slopes steeply down to depths greater than $250 \mathrm{~m}$ (Roberts et al., 2005a). MRC5N is another ridge about $2 \mathrm{~km}$ long, oriented SW-NE. It slopes gently down from 109 to $240 \mathrm{~m}$ depth. Seabed sediments adjacent to the reefs are predominantly muddy, with extensive grounds of crinoids (Roberts et al., 2005a).

\subsection{Seabed habitat mapping and benthic sampling}

\subsubsection{Seabed bathymetry}

A remote-sensing multibeam sonar survey of MRC1 and MRC5N was conducted on board the R/V Pelagia in June 2006 using a hull-mounted $30 \mathrm{kHz}$ Kongsberg EM300 multibeam echosounder (Maier, 2006; Roberts et al., 2009). Several seabed terrain variables were derived for sites where 


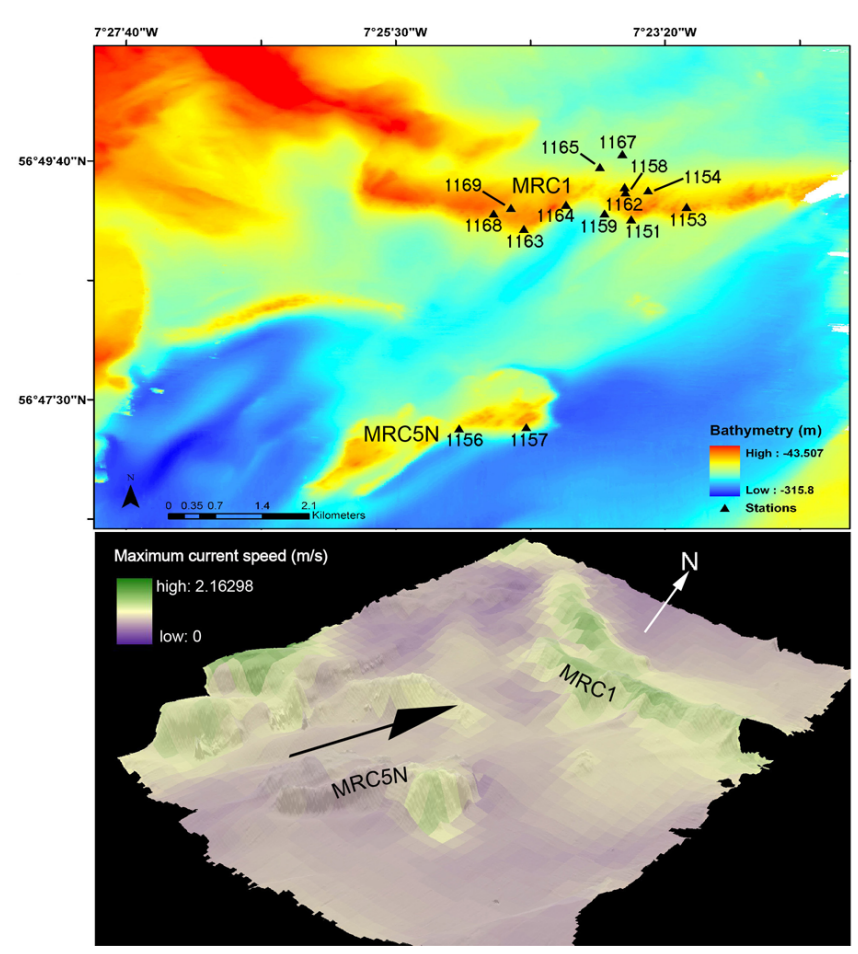

Fig. 2. Grab stations on the reef complex $(n=14)$ in relation to bathymetry (top) and hydrography (bottom). In the bottom image, prevailing SSW to NNE currents are indicated by a black arrow, with north indicated by a white arrow. Mingulay Area $1=$ MRC1, Mingulay 5 North $=$ MRC5N.

benthic sampling took place (Table 1) using ArcGIS 9.2 with ESRI spatial analysis and Benthic Terrain Modeler extensions (Wright et al., 2005). Variables included depth, slope (degrees of inclination), aspect (the orientation of the grab sample on the seafloor measured in radians), rugosity (a nonmetric measure of topographic unevenness) and the bathymetric position index (BPI; a non-metric measure of whether the area is on a topographic "hill" or low "depression" relative to the surrounding area). The mean of each variable in a $10 \mathrm{~m}$ diameter buffer around each station was estimated as the rate of change between cells in a $3 \times 3$ neighbourhood (Table 1, Fig. 2). The $3 \times 3 \mathrm{~m}$ resolution bathymetric grid was then interpolated to a $100 \times 100 \mathrm{~m}$ grid in ArcGIS. Rugosity was positively correlated with slope $\left(R^{2}=0.97\right.$, $p<0.0001)$; therefore, only the latter was used in subsequent analyses.

\subsubsection{Local hydrography}

The hydrodynamic model 3DMOHID solves the equations of a three-dimensional flow for incompressible fluids and an equation of state relating density to salinity and temperature (Santos, 1995; Martins et al., 1998, 2001). The nested system consisted of two sub-components: a coarse-resolution outer model covering part of the Sea of the Hebrides with a fine-scale resolution inner model covering the Mingulay Reef Complex with a horizontal resolution of roughly $100 \mathrm{~m}$. The model ran for specific dates over seven days and covered the same measurement time for hydrographic lander stations described in Davies et al. (2009). Because hydrography at the complex is tidally driven (Davies et al., 2009), running the model over half a lunar cycle provided a reasonable approximation of water current conditions over the longer term. Average current speed $\left(C_{\mathrm{AVE}}\right)$, maximum current speed $\left(C_{\mathrm{MAX}}\right)$ and current speed standard deviation $\left(C_{\mathrm{SD}}\right)$ were calculated and exported as *.txt files to be integrated in a 3-D geographic information system. $C_{\mathrm{AVE}}, C_{\mathrm{MAX}}$ and $C_{\mathrm{SD}}$ were extracted from the spatially resolved model for each station and used as predictor variables for subsequent analyses (Table 1, Fig. 2).

\subsubsection{Benthos}

Benthic fauna were collected on board the MY Esperanza in May 2005 using a Van Veen grab that sampled an area of approximately $0.1 \mathrm{~m}^{2}$ each time it was deployed (Roberts et al., 2005b). A total of 14 grabs targeting reef framework were obtained (Table 1, Fig. 2) using a random-nested design yielding several replicates within a reef and between reefs. Grab contents were washed and sieved on-board at $1 \mathrm{~mm}$, stored in $4 \%$ borax-buffered seawater and transferred to $70 \%$ industrial methylated spirit. These were identified to the lowest possible taxonomic level, producing a list of 172 species (excluding sponges, which were excluded due to a lack of taxonomic resolution; Table S1 in the Supplement). Each species was classified into one of three functional guilds (sessile suspension or filter feeders, scavenging detritivores, or mobile predators) based on predominant feeding and mobility traits using data in the WoRMS registry (www.marinespecies.org) or based on the general biology of major taxa (Table S1 in the Supplement).

\subsection{Statistical analyses}

Species data were transformed to presence-absence data, followed by Hellinger distance transformation to give low weights to rare species and to preserve linear relationships between species and environmental gradients (Legendre and Gallagher, 2001).

The development of spatial eigenfunctions first required the pairwise Euclidean distances between all 14 sites $\left(d_{i j}\right)$ to be computed based on their Universal Transverse Mercator geographic co-ordinates to generate a distance matrix $\mathbf{D}$. A threshold value $t$ was then selected to truncate $\mathbf{D}$ to a new matrix $* \mathbf{D}$ according to the rules provided by Eq. (1):

$* \mathbf{D}=d_{i j}$ if $d_{i j} \leq \boldsymbol{t}$, and $4 t$ if $d_{i j}>\boldsymbol{t}$.

A $t$ value of $993.62 \mathrm{~m}$ was chosen as this was the greatest distance between neighbouring sites and thus the minimum distance that would keep all 14 sites connected. Pairwise 
Table 1. Topographic and hydrographic variables for each of the 14 sites at the reef complex.

\begin{tabular}{|c|c|c|c|c|c|c|c|c|c|c|}
\hline Site & Latitude & Longitude & $\begin{array}{l}C_{\mathrm{AVE}} \\
\mathrm{m} \mathrm{s}^{-1}\end{array}$ & $\begin{array}{c}C_{\mathrm{MAX}} \\
\mathrm{ms}^{-1}\end{array}$ & $\begin{array}{r}C_{\mathrm{SD}} \\
\mathrm{m} \mathrm{s}^{-1}\end{array}$ & BPI & $\begin{array}{r}\text { Aspect } \\
(\text { deg rad })\end{array}$ & Rugosity & $\begin{array}{r}\text { Slope } \\
\left({ }^{\circ}\right)\end{array}$ & $\begin{array}{r}\text { Depth } \\
(\mathrm{m})\end{array}$ \\
\hline 1151 & 56.81896 & -7.39345 & 0.277 & 0.387 & 0.065 & -6 & 239.7 & 1.0181 & 8.4 & 121 \\
\hline 1153 & 56.82083 & -7.386 & 0.339 & 0.559 & 0.123 & -16 & 138 & 1.0078 & 4.1 & 126 \\
\hline 1154 & 56.8233 & -7.391166 & 0.335 & 0.616 & 0.15 & -12 & 5.7 & 1.0112 & 6.1 & 146 \\
\hline 1156 & 56.78733 & -7.4165 & 0.33 & 0.549 & 0.116 & 123 & 0.5 & 1.0663 & 15.2 & 140 \\
\hline 1157 & 56.7875 & -7.4075 & 0.256 & 0.428 & 0.071 & 94 & 97.8 & 1.1705 & 26.6 & 122 \\
\hline 1158 & 56.82383 & -7.39433 & 0.336 & 0.637 & 0.157 & 34 & 275.3 & 1.0363 & 10.4 & 138 \\
\hline 1159 & 56.81983 & -7.397 & 0.324 & 0.575 & 0.135 & -6 & 239.7 & 1.0181 & 8.4 & 155 \\
\hline 1162 & 56.823016 & -7.3942 & 0.321 & 0.599 & 0.142 & 34 & 275.3 & 1.0363 & 10.4 & 129 \\
\hline 1163 & 56.8175 & -7.40783 & 0.336 & 0.637 & 0.157 & -25 & 122.8 & 1.1124 & 19.3 & 125 \\
\hline 1164 & 56.821166 & -7.402166 & 0.282 & 0.463 & 0.091 & 42 & 89.7 & 1.0402 & 11.6 & 128 \\
\hline 1165 & 56.82685 & -7.397633 & 0.314 & 0.523 & 0.115 & 1 & 334.8 & 1.0061 & 4.6 & 174 \\
\hline 1167 & 56.8288166 & -7.39463 & 0.297 & 0.45 & 0.077 & 1 & 334.8 & 1.0061 & 4.6 & 187 \\
\hline 1168 & 56.819816 & -7.411883 & 0.336 & 0.637 & 0.157 & -17 & 201.7 & 1.0123 & 7.2 & 125 \\
\hline 1169 & 56.820666 & -7.40955 & 0.344 & 0.604 & 0.135 & -17 & 201.7 & 1.0123 & 7.2 & 128 \\
\hline
\end{tabular}

distances $>993.62 \mathrm{~m}$ were therefore changed to a value of $4 \times 993.62 \mathrm{~m}=3974.48 \mathrm{~m}$. Principal coordinate analysis of the truncated matrix $* \mathbf{D}$ was followed by a restriction to only positive eigenvalues, yielding eight spatial scales (eigenfunctions) of positive autocorrelation in the study area (Table 2).

To avoid overfitting any models and inflating Type I error, a subset of eigenfunctions was selected using a stepwise forward selection procedure (Blanchet et al., 2008) to maximise the adjusted amount of explained variance while balancing Type I error rates. Forward selection of variables in this way resulted in fewer spatial "submodels" that most strongly related to variation in species assembly.

Canonical variance partitioning was used to decompose the total variation in community assembly into variation explained by the environment, space, spatially structured environment and residual (unexplained) mechanisms. Redundancy analysis (RDA) for each submodel was performed first with the full suite of forward selected variables, followed by partial redundancy analyses (pRDAs) controlling for the effects of either spatial or environmental covariables (Borcard et al., 2004).

\section{Results}

\subsection{Reduction in the number of explanatory variables}

The dbMEM analysis identified 13 eigenvalues, the first eight of which had positive values and which were therefore retained as variables that represented positive spatial autocorrelation (Table 2).

The full suite of eight eigenfunctions explained $61 \%$ of the variation in community assembly. Forward selection identified a reduced set of five (Eig2, 3, 4, 5 and 7; Table 2), the combination of which explained $45 \%$ of the variation in community assembly. This reduced subset of variables represented two types of spatial submodels: broadscale (inter-reef and across reef distances of hundreds of metres to several kilometres) and fine-scale (within reef distances of tens to a few hundred metres).

The full suite of environmental variables explained a total of $56 \%$ of the variation in assembly. Forward selection of environmental variables reduced this set of variables to two topographic (aspect and BPI) and two hydrographic $\left(C_{\mathrm{MAX}}\right.$ and $C_{\mathrm{SD}}$ ) variables, which explained nearly as much variation, with $40 \%$ of changes in community composition attributed to gradients in these key variables.

\subsection{Drivers of broad-scale community assembly}

The full broad-scale RDA model (a combination of $C_{\mathrm{MAX}}$, current speed variability $C_{\mathrm{SD}}$, aspect, BPI, and the eigenfunctions 2, 3 and 4$)$ explained $65 \%(p=0.04)$ of the variation in reef species assembly (Table 3 ).

When the effects of space were excluded by partialling out their effects in the redundancy analysis (Table 3), species assembly was significantly related to environmental heterogeneity $(p=0.048)$. The first two axes were closely correlated with topography and hydrography, respectively (Fig. 3). In contrast, the effects of space alone (controlling for environmental variability) were not statistically significant at broad spatial scales $(p=0.146)$.

The distribution of filter and suspension feeders varied across environmental gradients (Fig. 4). While some species appeared to inhabit topographically raised seabed areas, others preferred to face directly into currents that were both temporally dynamic and very fast (up to $64 \mathrm{~cm} \mathrm{~s}^{-1}$ ). Assembly of predators and detritivores also varied across the bathymetric gradient (Fig. 4), with some exhibiting clear preferences for facing into the current on topographic highs, while others inhabited local seabed depressions with slower currents. 
Table 2. Spatial eigenfunctions representing scales of positive autocorrelation detected in communities across the reef complex. A reduced set of five eigenfunctions (* broad-scale, ** fine-scale) explained much of the variation in assembly.

\begin{tabular}{rrrrrrrr}
\hline Eig1 & *Eig2 & *Eig3 & *Eig4 & $* *$ Eig5 & Eig6 & **Eig7 & Eig8 \\
\hline 846.67 & -531.18 & 1586.73 & -731.95 & 163.25 & -81.06 & -0.04 & -5.91 \\
1310.68 & 101.78 & 1281.41 & 273.37 & -983.02 & -61.53 & 0.04 & -9.87 \\
1569.61 & 467.60 & -24.62 & -544.51 & -279.71 & -192.27 & 0.06 & 21.69 \\
-1858.46 & 2385.39 & 564.64 & 322.74 & 247.16 & -0.01 & -275.12 & 0.06 \\
-1858.46 & 2385.39 & 564.63 & 322.75 & 247.16 & 0.11 & 275.12 & 0.06 \\
1192.36 & -93.24 & -573.72 & 817.75 & -158.78 & -5.36 & -0.03 & 25.27 \\
451.43 & -1121.20 & 1035.84 & 652.95 & 304.02 & 152.41 & $-8.57 \times 10^{-5}$ & 15.78 \\
1191.50 & -101.67 & -555.26 & 829.36 & -160.62 & -75.18 & -0.01 & -31.02 \\
-1928.13 & -1746.72 & 539.40 & -1002.66 & 755.76 & -4.48 & $1.92 \times 10^{-3}$ & 0.18 \\
629.37 & -782.68 & -257.74 & -129.53 & 1019.70 & -71.81 & 0.04 & -9.85 \\
1541.34 & 490.23 & -131.74 & -580.84 & -202.78 & 349.43 & -0.06 & -6.37 \\
884.45 & 1043.04 & -2274.69 & -795.91 & 465.29 & -14.78 & $2.30 \times 10^{-3}$ & 0.04 \\
-2410.64 & -865.24 & -788.05 & -812.64 & -1477.41 & 4.06 & $-1.17 \times 10^{-3}$ & -0.09 \\
-1561.71 & -1631.51 & -966.83 & 1379.12 & 59.98 & 0.49 & $-1.09 \times 10^{-3}$ & 0.04 \\
\hline
\end{tabular}

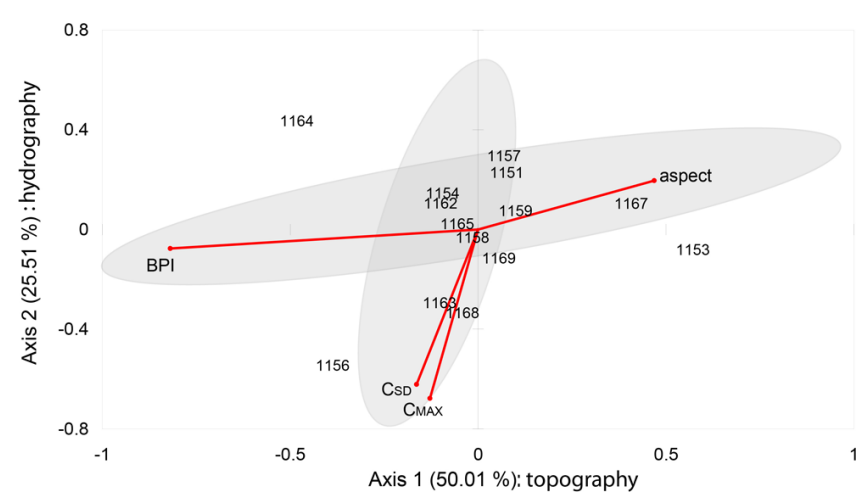

Fig. 3. Environmental control of assembly at broad (across reef) spatial scales determined by topographic variation in BPI and aspect (near horizontal shaded ellipse) and hydrographic variability in $C_{\mathrm{MAX}}$ and $C_{\mathrm{SD}}$ (near vertical shaded ellipse). Line length reflects the strength of a variable with respect to community assembly. Sites are also indicated to demonstrate the wide range of environmental settings that control species and functional assembly of reef communities.

Generally, predators and detritivores were more narrowly distributed across the hydrography axis (Fig. 4). This reflected an overall more narrow hydrographic niche characterised by slower and less variable currents. Few species were correlated with fast variable currents, but even these were not as strongly related to these environments as some sessile fauna (Fig. 4).

\subsection{Drivers of fine-scale community assembly}

The full fine-scale RDA model $\left(C_{\mathrm{MAX}}, C_{\mathrm{SD}}\right.$, aspect, BPI, eigenfunctions 5 and 7 ) explained $58.9 \%$ of the variation in species assembly ( $p=0.034$; Table 3 ). The first and second axes closely related to eigenfunctions 5 and 7 , respectively.
Table 3. Redundancy and partial redundancy analyses that quantified the amount $(\%)$ of community assembly variability explained by pure environmental (env), spatial (space), and spatially structured environmental variables $\left(\mathrm{env}_{\mathrm{space}}\right)$, alongside the statistical significance of the model (set at $p<0.05$, indicated by $*$ ), which for env $_{\text {space }}$ cannot be estimated using any method (Bocard et al., 2004) and thus was not applicable (NA).

\begin{tabular}{lrr}
\hline $\begin{array}{l}\text { Spatial } \\
\text { model }\end{array}$ & $\begin{array}{r}\text { variability } \\
\text { explained (\%) }\end{array}$ & $p$ \\
\hline Broad-scale & & \\
\hline env + space + env $_{\text {space }}$ & 65.0 & $0.040^{*}$ \\
pure env & 36.6 & $0.048^{*}$ \\
pure space & 23.9 & 0.146 \\
pure env & 4.5 & $\mathrm{NA}$ \\
unexplained variance & 35.0 & $\mathrm{NA}$ \\
\hline Fine-scale & & \\
\hline env + space + env & & \\
pure env & 58.9 & $0.034^{*}$ \\
pure space & 37.0 & 0.096 \\
pure env & 17.8 & $0.036^{*}$ \\
unexplained variance & 4.0 & $\mathrm{NA}$ \\
& 41.1 & $\mathrm{NA}$ \\
\hline
\end{tabular}

Bathymetry alone did not explain a statistically significant amount of variation in the fine-scale assembly of reef communities ( $p=0.096)$, whereas space accounted for a significant proportion of the variation $(p=0.036)$.

A subset of species was strongly related to eigenfunctions 5 and 7 including sessile species of serpulid polychaete worms, hydroids, bryozoans and anomiid bivalve molluscs (Fig. 4). Species-specific life history information indicates a predominance of larval dispersal strategies in these species, that produce in clumps of recruits, e.g. philopatry (see 


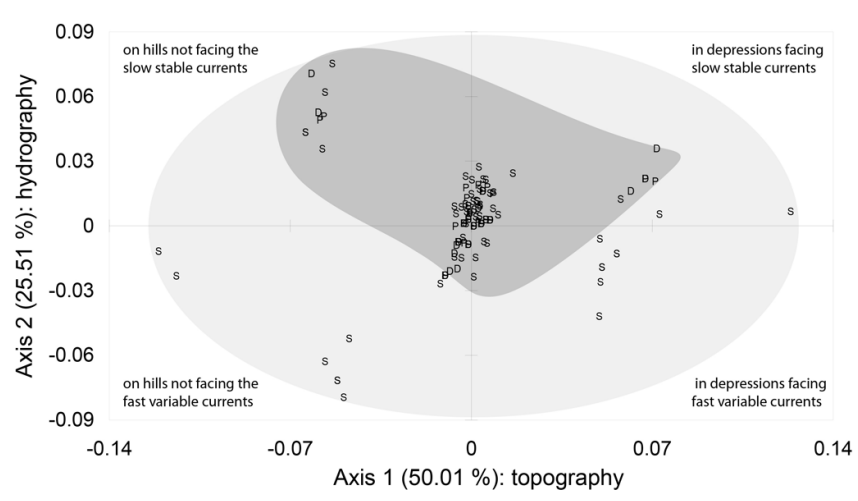

Fig. 4. Environmental control of functional guild assembly. Mobile scavenging detritivore (D) and predator $(\mathrm{P})$ species were distributed across more narrow environmental niches (dark grey shaded area) than sessile filter and suspension feeders (S), the latter of which were found across all sets of topographic and hydrographic conditions (light grey shaded area). Mobile fauna inhabited sites with slower, less dynamic currents, while sessile fauna colonised every type of habitat at the reef.

Sect. 4.2.1). Paradoxically, detritivores and predators that have mobility were also associated with these eigenfunctions (Fig. 4), but mechanisms other than restricted dispersal were likely responsible (see Sect. 4.2.2).

\section{Discussion}

Our multi-scale analyses identified a common set of community assembly drivers across a phylogenetically and functionally diverse range of taxa. Bathymetry, hydrography and species' ecology interact to produce different scales of assembly on the reef complex. However the underlying mechanisms that produce these patterns were highly dependent on species' ecology and life histories. This underscores the importance of having highly resolved taxonomic data and information on the basic natural history of species at hand for a post-phylogenetic and trait-based era of community assembly paradigms.

The assembly of sessile suspension and filter feeder species was primarily constrained by their need for a food supply, metabolic requirements and dispersal, all of which closely link these species to the interactive effects of currents impinging on seabed topography. Scavenging detritivores and mobile predators were also non-uniformly distributed across the reef complex, but assembly of these communities became more closely linked to energetic and behavioural constraints at finer spatial scales.

\subsection{Broad-scale environmental control of community assembly}

The net effect of environmental variability across a marine seascape can induce spatial variability in the distribution of functional traits (Hewitt et al., 2008). Our study demonstrated that environmental gradients were very important to the broad-scale (hundreds of metres to several kilometres) spatial structure of species and trait assembly at the Mingulay Reef Complex. Topographic variations in BPI, aspect and changes in hydrography across many hundreds of metres to several kilometres were particularly important in creating different seabed environments, which in turn supported distinct faunal and functional communities.

\subsubsection{Interactive effects of topography and hydrography on sessile fauna}

Filter and suspension feeders were widely distributed across the reef complex, but species composition changed across topographic and hydrographic gradients. Current speeds affect particle capture rates among passive suspension feeders in a species-specific way (Shimeta, 2009) that affects population dynamics of sessile suspension feeders (Arkema, 2009).

Few of the suspension-feeding fauna at Mingulay were observed facing directly into prevailing, fast-flowing currents. Those most strongly associated with this environmental setting had a low-lying encrusting morphology that adapts an organism to high flow regimes by maximising particle capture efficiency. At Mingulay, this encrusting fauna included the barnacle Verruca stroemia, the bryozoans Diplosolen obelia and Schizomavella hastata, and the anomiid bivalves Heteranomia squamula and Monia patelliformis.

\subsubsection{Energetic and behavioural constraints on mobile fauna assembly}

Significant faunal turnover at spatial scales of tens to hundreds of metres has been attributed to changes in topographic and hydrographic steering of food on continental shelf and deep-sea canyon ecosystems (Schneider et al., 1987; McClain and Barry, 2010). Hydrographic variation also drives assembly at the Mingulay Reef Complex, with a striking lack of macrofaunal predators and scavengers in fast dynamic flow regimes. These patterns reflect energetic balances between obtaining food, mates and social interactions and having to expend resources to move in a fast variable flow regime. Slower less dynamic currents provide a temporally stable flux of detritus to the seabed, while pulsed episodes of food particle delivery can elicit a rapid but temporary aggregating response in mobile deep-sea fauna (Bett et al., 2001). Fast dynamic currents may also dilute and mix chemical cues used by crabs and shrimps to detect prey (Power and Kittinger, 2002); this could explain the close association of predators such as the polychaetes Glycera 


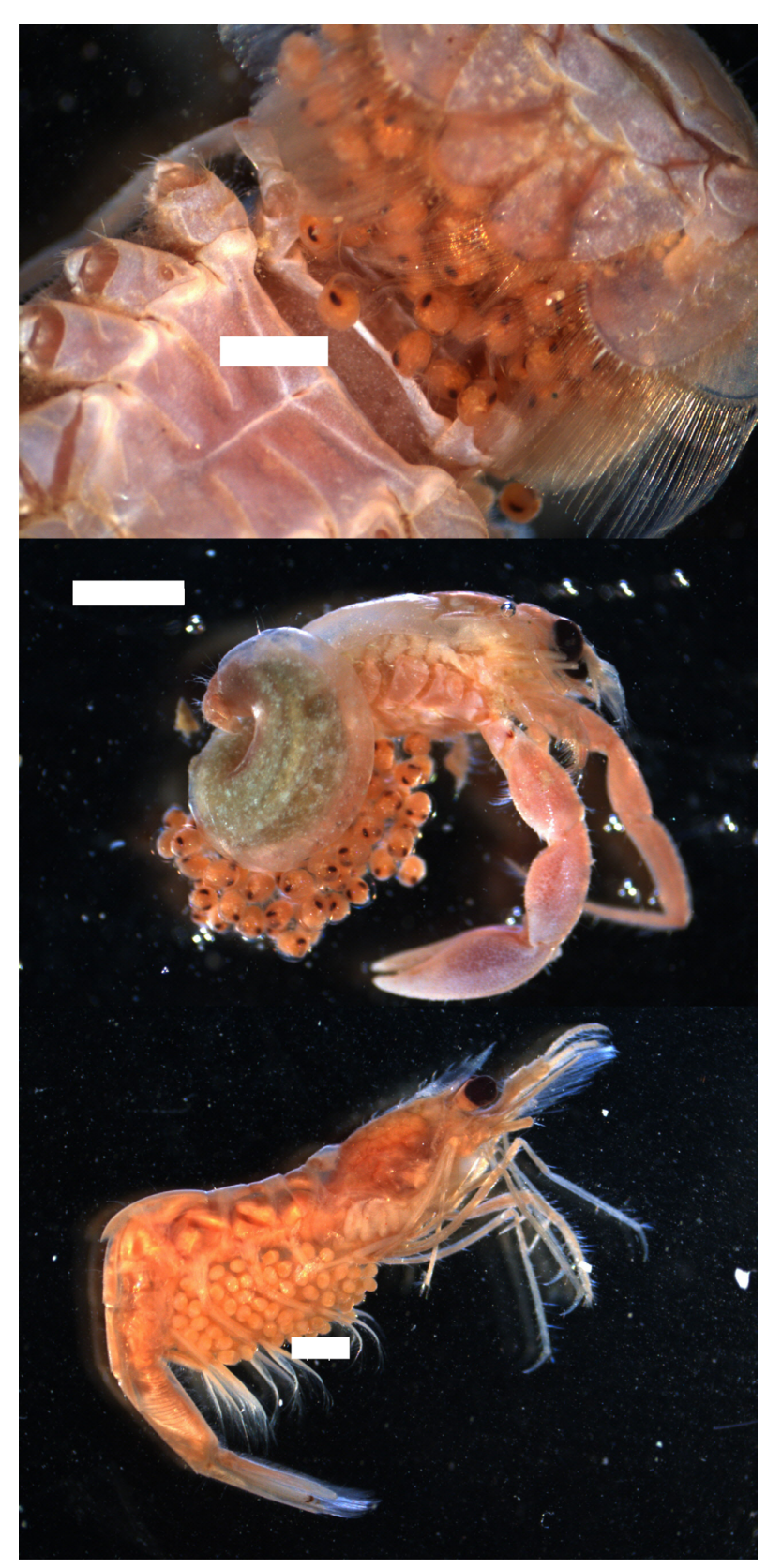

Fig. 5. Gravid decapod crustaceans on the reef complex. Top: the galatheid crab Munida sarsi, white scale $=1 \mathrm{~mm}$. Middle: the hermit crab (shell removed) Pagurus forbesii, white scale $=2 \mathrm{~mm}$. Bottom: the pandalid shrimp Pandalina brevirostris, white scale $=1 \mathrm{~mm}$.

lapidum and Eunice norvegica, the crabs Xantho hydrophilus and Munida sarsi, and the spongivore limpet Emarginula fissura with slower currents. Munida sarsi uses ambush tactics to capture prey from burrows (Hudson and Wigham, 2003), which could explain why $M$. sarsi occurs in less hydrodynamic environments.

\subsection{Fine-scale assembly and spatial autocorrelation}

Environmental control of sessile suspension feeders at Mingulay was previously detected at broad spatial scales (Henry et al., 2010). However significant and relatively more important effects of spatial autocorrelation were detected at finer spatial scales using the multi-scale dbMEM approach. Environmental decoupling at small spatial scales is consistent with other patterns detected by dbMEM in lotic gastropod assemblages (Hauffe et al., 2011) and spatially autocorrelated patches of megafauna inhabiting fjords at the same spatial scale from tens to a few hundreds of metres (Gonzalez-Mirelis et al., 2009). Uncovering the mechanisms that create fine-scale spatial structure requires knowledge of species autoecology and natural history. Sessile fauna that tended to be spatially aggregated were those that exhibit strong levels of limited dispersal arising through philopatry or gregarious larval settlement. Spatially aggregated mobile fauna tended to be crabs and shrimp that may have been aggregating for social interaction. It is unlikely that these trends reflected an undersampled mobile fauna: although not as mobile as fish, video observations of decapod crustaceans at Mingulay show many of these animals, particularly $\mathrm{Mu}$ nida sarsi, remaining in their patches during sampling instead of escaping. However increased grab replication within each spatial submodel could reveal even finer scale structuring at tens of centimetres to metres.

\subsubsection{Dispersal limitation in sessile reef organisms}

Sessile fauna at Mingulay that exhibited the strongest degree of spatial autocorrelation at fine scales exhibit life history strategies that promote the retention of larvae and recruits near the adult. The serpulid polychaetes Hydroides norvegicus and Serpula vermicularis were closely related to the spatial eigenfunctions Eig5 and 7, and both are known to exhibit gregarious larval settlement (Bosence, 1979; Keough, 1983). The hydroid Eudendrium sp. also exhibited strong patterns of spatial autocorrelation, which may be due to a strong tendency for philopatry in eudendriids (Sommer, 1992; Oliveira and Marques, 2005).

\subsubsection{Social mediation of decapod aggregations}

Spatial autocorrelation of local communities is expected to be less prevalent in highly mobile fauna (Weiher et al., 2011): individuals are assumed to freely forage and socialise across large home ranges, with their mobility effectively erasing barriers to dispersal. But the assembly of mobile organisms can be spatially aggregated in marine ecosystems (Schneider et al., 1987; Becking et al., 2006), a phenomenon that requires explanations beyond dispersal capabilities.

Spatially autocorrelated krill swarms do not arise because of hydrography or topography, but because these animals aggregate by active locomotion (Krafft et al., 2012) that may 
relate to social foraging (Laidre, 2012). Alternatively, aggregations may arise because of mating behaviours: coastal brachyuran crabs in the northwest Atlantic aggregate at the same spatial scales as those at Mingulay, from tens to a hundred metres (Sainte Marie et al., 1999). Many of the crabs and shrimp collected during our surveys were gravid including Munida sarsi, Pagurus forbesii, and Pandalina brevirostris (Fig. 5), and juveniles were frequently encountered, which could also indicate recent or on-going mating events in these species. Aggregations of predators may also be related to fine-scale patches in prey recruitment (White, 2007), which in turn may depend on levels of predation that selects for restricted prey dispersal (Barraquand and Murrell, 2012). These local community dynamics highlight the importance of disentangling the interactive effects of density dependence on spatial structure in marine communities (Hewitt et al., 2008).

\section{Conclusions}

There is an urgent need to assess the cumulative impacts of human activities and unprecedented rates of climate change on the deep seafloor environment (Nellemann et al., 2008). Critical to this assessment is an understanding of the spatial scales at which these changes will alter the environment its control on biological communities and ecosystems.

Multi-scale analyses help avoid spatial mismatches in making these assessments that would otherwise occur when studies are conducted at smaller or larger spatial scales than those at which environmental controls or intrinsic processes actually operate (Gallucci et al., 2009). Marine spatial planning for the Mingulay Reef Complex will therefore require cumulative impact studies that appropriately consider all scales of human impacts (cf. Foley et al., 2010), from renewable energy installations that can modify broad-scale hydrography to the effects of bottom fishing that can reduce reef connectivity for dispersal-limited organisms.

\section{Supplementary material related to this article is available online at: $\mathrm{http}: / / \mathrm{www} . b i o g e o s c i e n c e s . n e t / 10 /$ 2737/2013/bg-10-2737-2013-supplement.pdf.}

Acknowledgements. Funding was provided by the European Sixth Framework projects ECCRE (Marie Curie international fellowship to L-AH), HERMES (grant agreement no. 511234 to JMR) and the Seventh Framework Project HERMIONE (grant agreement no. 226354 to JMR). Development of the hydrodynamic model was supported by Heriot-Watt University's Environment and Climate Change theme. The authors thank the captains, scientific personnel and crews of the R/V Pelagia (Royal Netherlands Institute for Sea Research) and MY Esperanza (Greenpeace) for assistance at sea to collect data. We thank two anonymous reviewers and R. S. Santos for editorial handling.

Edited by: R. S. Santos

\section{References}

Arkema, K. K.: Flow-mediated feeding in the field: consequences for the performance and abundance of a sessile marine invertebrate, Mar. Ecol. Prog. Ser., 388, 207-220, 2009.

Barraquand, F. and Murrell, D. J.: Intense or spatially heterogeneous predation can select against prey dispersal, PLoS ONE, 7, e2892, 2012.

Becking, L. E., Cleary, D. F. R., de Voogd, N. J., Renema, W., de Beer, M., van Soest, R. W. M., and Hoeksema, B. W.: Beta diversity of tropical marine benthic assemblages in the Spermonde Archipelago, Indonesia, Mar. Ecol., 27, 76-88, 2006.

Bett, B. J., Malzone, B. E., Narayanaswamy, B. E., and Wigham, B. D.: Temporal variability in phytodetritus and megabenthic activity at the seabed in the deep Northeast Atlantic, Prog. Oceanogr., 50, 349-368, 2001.

Blanchet, F. G., Legendre, P., and Borcard, D.: Forward selection of explanatory variables, Ecology, 89, 2623-2632, 2008.

Blanquer, A., Uriz, M.-J., and Caujapé, J.: Small-scale spatial genetic structure in Scopalina lophyropoda, an encrusting sponge with philopatric larval dispersal and frequent fission and fusion events, Mar. Ecol. Prog. Ser., 380, 95-102, 2009.

Borcard, D. and Legendre, P.: All-scale spatial analysis of ecological data by means of principal coordinates of neighbour matrices, Ecol. Model., 153, 51-68, 2002.

Borcard, D., Legendre, P., Avois-Jacquet, C., and Tuomisto, H.: Dissecting the spatial structure of ecological data at multiple scales, Ecology, 85, 1826-1832, 2004.

Bosence, D. W. J.: The factors leading to aggregation and reef formation in Serpula vermicularis L. In, Proceedings of an International Symposium held at the University of Durham, April 1976 , Biology and Systematics of Colonial Organisms, edited by: Larwood, G. and Rosen, B. R., London, Academic Press, 299-318, 1979.

Cadotte, M. W., Carscadden, K., and Mirotchnick, N.: Beyond species: functional diversity and the maintenance of ecological processes and services, J. Appl. Ecol., 48, 1079-1087, 2011.

Davies, A. J., Duineveld, G., Lavaleye, M., Bergman, M. J., van Haren, H., and Roberts, J. M.: Downwelling and deep-water bottom currents as food supply mechanisms to the coldwater Lophelia pertusa (Scleractinia) at the Mingulay reef complex, Limnol. Oceanogr., 54, 620-629, 2009.

De Bello, F., Lavorel, S., Díaz, S., Harrington, R., Bardgett, R., Berg, M., Cipriotti, P., Cornelissen, H., Feld, C., Hering, D., Martins da Silva, P., Potts, S., Sandin, L., Sousa, J. P., Storkey, J., and Wardle, D.: Functional traits underlie the delivery of ecosystem services across different trophic levels, Biodivers. Conserv., 143, 2873-2893, 2010.

de Voogd, N., Cleary, D. F. R., Hoeksema, B. W., Noor, A., and van Soest, R. W. M.: Sponge beta diversity in the Spermonde Archipelago, SW Sulawesi, Indonesia, Mar. Ecol. Prog. Ser., 309, 131-142, 2006.

Dray S., Legendre, P., and Peres-Neto, P. R.: Spatial modelling: a comprehensive framework for principal coordinate analysis of neighbour matrices (PCNM), Ecol. Model., 196, 483-493, 2006.

Duineveld, G. C. A., Jeffreys, R. M., Lavaleye, M. S. S., Davies, A. J., Bergman, M. J. N., Watmough, T., and Witbaard, R.: Spatial and tidal variation in food supply to shallow cold-water coral reefs on the Mingulay Reef Complex (Outer Hebrides, Scotland), Mar. Ecol. Prog. Ser., 444, 97-115, 2012. 
Foley, M. M., Halpern, B. S., Micheli, F., Armsby, M. H., Caldwell, M. R., Crain, C. M., Prahler, E., Rohr, N., Sivas, D., Beck, M. W., Carr, M. H., Crowder, L. B., Duffy, J. E., Hacker, S. D., McLeod, K. L., Palumbi, S. R., Peterson, C. H., Regan, H. M., Ruckelshaus, M. H., Sandifer, P. A., and Steneck, R. S.: Guiding ecological principles for marine spatial planning, Mar. Policy, 34, 955-966, 2010.

Gallucci, F., Moens, T., and Fonesca, G.: Small-scale patterns of meibenthos in the Arctic deep sea, Mar. Biodivers., 39, 9-25, 2009.

Gonzalez-Mirelis, G., Bergström, P., Lundälv, T., Jonsson, J., and Lindegarth, M.: Mapping the benthos: spatial patterns of seabeddwelling megafauna in a Swedish fjord, as derived from opportunistic video data, Mar. Biodivers., 39, 291-302, 2009.

Hauffe, T., Albrecht, C., Schreiber, K., Birkhofer, K., Trajanovski, S., and Wilke, T.: Spatially explicit analysis of gastropod biodiversity in ancient Lake Ohrid, Biogeosciences, 8, 175-188, doi:10.5194/bg-8-175-2011, 2011.

Henry, L.-A., Davies, A. J., and Roberts, J. M.: Beta diversity of cold-water coral reef communities off western Scotland, Coral Reefs, 29, 427-436, 2010.

Henry, L.-A., Moreno Navas, J., Hennige, S. J., Wicks, L. C., Vad, J., and Roberts, J. M.: Cold-water coral reef habitats benefit recreationally valuable sharks, Biol. Cons., 161, 67-70, doi:10.1016/j.biocon.2013.03.002, 2013.

Hewitt, J. E., Thrush, S. F., and Dayton, P. D.: Habitat variation, species diversity and ecological functioning in a marine system, J. Exp. Mar. Biol. Ecol., 366, 116-122, 2008.

Hudson, I. R. and Wigham, B. D.: In situ observations of predatory feeding behaviour of the galatheid squat lobster Munida sarsi using a remotely operated vehicle, J. Mar. Biol. Assoc. UK, 83, 463-463, 2003.

Keough, M. J.: Patterns of recruitment of sessile invertebrates in two subtidal habitats, J. Exp. Mar. Biol. Ecol., 66, 213-245, 1983.

Krafft, B. A., Skaret, G., Knutsen, T., Melle, W., Klevjer, T., and Søiland, H.: Antarctic krill swarm characteristics in the Southeast Atlantic sector of the Southern Ocean, Mar. Ecol. Prog. Ser., 465, 69-83, 2012.

Laidre, M. E.: Foraging across ecosystems: diet diversity and social foraging spanning aquatic and terrestrial ecosystems by an invertebrate, Mar. Ecol., 34, 80-89, doi:10.1111/j.14390485.2012.00527.x, 2012.

Lavorel, S., Grigulis, K., Lamarque, P., Colace, M.-P., Garden, D., Girel, J., Pellet, G., and Douzet, R.: Using plant functional traits to understand the landscape distribution of multiple ecosystem services, J. Ecol., 99, 135-147, 2011.

Legendre, P. D. and Gallagher, E. D.: Ecologically meaningful transformations for ordination of species data, Oecologia, 129, 271-280, 2001.

Maier, C.: Biology and ecosystem functioning of cold water coral bioherms at Mingulay (Hebrides), NE Atlantic. Cruise Report, BIOSYS 2006 Cruise 64PE250 on R/V Pelagia, Oban-Oban, 7-23 July 2006, Royal Netherlands Institute for Sea Research, Texel, 2006.

Martins, F. A., Neves, R. J., and Leitão, P. C.: A three-dimensional hydrodynamic model with generic vertical coordinate, in: Proceedings of Hidroinformatics, edited by: Babovic, V. and Larsen, L. C., 98, 2, Balkerna/Rotterdam, Copenhague, Denmark, August 1998, 1403-1410, 1998.
Martins, F. A., Leitao, P. C., Silva, A., and Neves, R. J.: 3D modelling in the Sado estuary using a new generic vertical discretization approach, Oceanol. Acta, 24, 51-62, 2001.

McClain, C. R. and Barry, J. P.: Habitat heterogeneity, disturbance, and productivity work in concert to regulate biodiversity in deep submarine canyons, Ecology, 91, 964-976, 2010.

McClain, C. R., Allen, A. P., Tittensor, D. P., and Rex, M. A.: Energetics of life on the deep seafloor, Proc. Nat. Acad. Sci., 109, 15366-15371, doi:10.1073/pnas.1208976109, 2012.

Moreno Navas, J., Telfer, T. C., and Ross, L. G.: Application of a $3 \mathrm{D}$ hydrodynamic and particle tracking models for better environmental management of finfish culture, Cont. Shelf Res., 31, 675-684, 2011.

Moreno Navas, J., Miller, P., Henry, L.-A., and Roberts, J. M.: Ecohydrodynamics of cold-water coral reefs: a case study of the Mingulay Reef Complex, PLoS One, submitted, 2013.

Mouillot, D., Villéger, S., Scherer-Lorenzen, M., and Mason, N. W. H.: Functional structure of biological communities predicts ecosystem multifunctionality, PLoS ONE, 6, e17476, 2011.

Nellemann, C., Hain, S., and Alder, J. (Eds): In Dead Water - Merging of climate change with pollution, over-harvest, and infestations in the world's fishing grounds, United Nations Environment Programme, GRID-Arendal, Norway, 2008.

Oliveira, O. M. P. and Marques, A. C.: Population biology of Eudendrium caraiuru (Cnidaria, Anthoathecata, Eudendriidae) from São Sebastião Channel, Southeastern Brazil, Ihering, Sér. Zool., 95, 241-246, 2005.

Power, S. P. and Kittinger, J. N.: Hydrodynamic mediation of predator-prey interactions: differential patterns of prey susceptibility and predator success explained by variation in water flow, J. Exp. Mar. Biol. Ecol., 273, 171-187, 2002.

Reu, B., Zaehle, S., Proulx, R., Bohn, K., Kleidon, A., Pavlick, R., and Schmidtlein, S.: The role of plant functional trade-offs for biodiversity changes and biome shifts under scenarios of global climatic change, Biogeosciences, 8, 1255-1266, doi:10.5194/bg8-1255-2011, 2011.

Roberts, J. M., Brown, C. J., Long, D., and Bates, C. R.: Acoustic mapping using a multibeam echosounder reveals coldwater coral reefs and surrounding habitats, Coral Reefs, 24, 654-669, 2005a.

Roberts, J. M., Davies, A. J., Dodds, L. A., and Santillo, D.: Report of the MY Esperanza cold-water coral research cruise to the Mingulay reef complex, 11-20 May 2005, Cruise Report for the Scottish Association for Marine Science and Greenpeace, $2005 \mathrm{~b}$.

Roberts, J. M., Davies, A. J., Henry, L.-A., Dodds, L. A., Duineveld, G. C. A., Lavaleye, M. S. S., Maier, C., van Soest, R. W. M., Bergman, M. I. N., Hühnerbach, V., Huvenne, V. A. I., Sinclair, D. J., Watmough, T., Long, D., Green, S. L., and van Haren, H.: The Mingulay reef complex, northeast Atlantic: an interdisciplinary study of cold-water coral habitat, hydrography and biodiversity, Mar. Ecol. Prog. Ser., 397, 139-151, 2009.

Sainte Marie, B., Urbani, N., Sévigny, J.-M., Hazel, F., and Kuhnlein, U.: Multiple choice criteria and the dynamics of assortative mating during the breeding season of female snow crab Chionoecetes opilio (Brachyura, Majidae), Mar. Ecol. Prog. Ser., 181, 141-153, 1999.

Santos, A. P.: Modelo hidrodinámico de circulacáo oceaánica e estuarina, PhD Thesis, IST, Lisbon, 1995 (in Portuguese).

Schneider, D. C., Gagnon, J.-M., and Gilkinson, K. D.: Patchiness of epibenthic megafauna on the outer Grand Banks of Newfound- 
land, Mar. Ecol. Prog. Ser., 39, 1-13, 1987.

Shimeta, J.: Influence of flow speed on the functional response of a passive suspension feeder, the spionid polychaete Polydora cornuta, Mar. Biol., 156, 2451-2460, 2009.

Sommer, C.: Larval biology and dispersal of Eudendrium racemosum (Hydrozoa, Eudendriidae), Sci. Mar., 56, 205-211, 1992.

Thiem, Ø., Ravagnan, E., Fosså, J. H., and Berntsen, J.: Food supply mechanisms for cold-water corals along a continental shelf edge, J. Mar. Syst., 60, 207-219, 2006.

Vroom, P. S., Page, K. N., Peyton, K. A., and Kukea-Schulz, J. K.: Spatial heterogeneity of benthic communities with an emphasis on reef algae at French Frigate Shoals, Northwestern Hawai'ian Islands, Coral Reefs, 24, 574-581, 2005.
Weiher, E., Freund, D., Bunton, T., Stefanski, A., Lee, T., and Bentivenga, S.: Advances, challenges and a developing synthesis of ecological community assembly theory, Phil. Trans. R. Soc. B, 366, 2403-2413, 2011.

White, J. W.: Spatially correlated recruitment of a marine predator and its prey shapes the large-scale pattern of density-dependent prey mortality, Ecol. Lett., 10, 1054-1065, 2007.

Wright, D. J., Lundblad, E. R., Larkin, E. M., Rinehart, R. W., Murphy, J., Cary-Kothera, L., and Draganov, K.: ArcGIS Benthic Terrain Modeler, Corvallis, Oregon, Oregon State University, Davey Jones Locker Seafloor Mapping/Marine GIS Laboratory and NOAA Coastal Services Center, available at: http://csc. noaa.gov/digitalcoast/tools/btm/index.html, (last access: November 2012), 2005. 